\title{
Analisis Model Conceptual Change dengan Strategi Konflik Kognitif untuk Mengurangi Miskonsepsi Fisika dengan Metoda Library Research
}

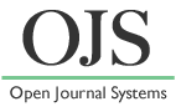

\author{
Tsaniyah Nabilah Rachmawati*, Z. A. Imam Supardi \\ Progam Studi Pendidikan Fisika, Jurusan Fisika, FMIPA, Universitas Negeri Surabaya. \\ Email: tsaniyah.17030184050@mhs.unesa.ac.id
}

DOI: https://doi.org/10.33369/pendipa.5.2.133-142

\begin{abstract}
The aim of this study was to describe the burden of student misconceptions in physics subjects, describe models of conceptual change learning can change students' understanding, analyze the use of cognitive conflict approaches to reduce student misconceptions in physics subjects. The main focus in this study was the relationship of conceptual change models with cognitive conflict approaches in reducing physical misconceptions. This research uses library research method, looking for relevant literature sources according to the topics discussed, with the aim of finding scientific and theoretical studies. This research uses data analysis techniques consisting of three stages, namely (1) orgainize, at this stage to group the literature - the literature studied. Literature must first be reviewed before use, in order to fit the subject matter. (2) synthesize, at this stage, unify the results of the grouping of literature in a concise and solid way. (3) identify, at this stage identify relevant and important issues to be reviewed and analyzed, in order to produce scientific paragraphs. The findings of this study are the burden of misconceptions that students have a high average in physics lessons, especially in temperature and heat matter. Misconceptions can come from students, teachers, books, and others. The use of conceptual change learning models with cognitive conflict strategies makes students active in completing their thinking independently, changing their understanding that needs to be updated. Making lessons meaningful and reducing misconceptions. The use of conceptual change models with cognitive conflict approaches significantly affects the reduction of misconceptions, updates concepts, and improves understanding and learning outcomes.
\end{abstract}

Keywords: Misconception; Conceptual change; Cognitive conflict; Physics; Understanding.

\begin{abstract}
ABSTRAK
Penelitian ini bertujuan mendeskripsikan beban miskonsepsi siswa pada mata pelajaran fisika, mendeskripsikan model pembelajaran conceptual change dapat merubah pemahaman siswa, menganalisis penggunaan strategi konflik kognitif untuk mereduksi miskonsepsi siswa pada mata pelajaran fisika. Fokus utama dalam penelitian ini adalah hubungan model perubahan konseptual dengan pendekatan konflik kognitif dalam mengurangi miskonsepsi fisika. Penelitian ini menggunakan metoda studi pustaka (library research), mencari sumber literatur yang relevan sesuai topik yang dibahas, dengan tujuan menemukan kajian ilmiah dan teoritis. Teknik analisis data yang digunakan dalam penelitian ini terdiri dari tiga tahapan yaitu (1) orgainize, pada tahap ini melakukan pengelompokkan literatur - literatur yang dikaji. Literatur harus terlebih dahulu di review sebelum digunakan, agar sesuai dengan pokok bahasan. (2) Synthesize, pada tahap ini melakukan penyatuan hasil pengelomppokkan literatur secara ringkas dan padu. (3) Identify, pada tahap ini mengidentifikasi permasalahan yang relevan dan penting untuk ditelaah dan dianalisis, agar menghasilkan paragraf yang ilmiah. Hasil penemuan penelitian ini adalah beban miskonsepsi yang dimiliki siswa rata rata tinggi dalam pelajaran fisika terutama dalam materi suhu dan kalor. Miskonsepsi dapat berasal dari siswa, guru, buku, dan lain - lain. Penggunaan model pembelajaran perubahan konseptual dengan strategi konflik kognitif menjadikan siswa aktif dalam menyelesaikan pemikirannya secara mandiri, mengubah pemahamannya yang perlu di perbarui. Membuat pelajaran
\end{abstract}


menjadi bermakna dan dapat mereduksi miskonsepsi. Penggunaan model conceptual change dengan strategi konflik kognitif berpengaruh secara signifikan terhadap penurunan miskonsepsi, memperbarui konsep, serta meningkatkan pemahaman dan hasil belajar.

Kata kunci: Miskonsepsi; Perubahan konseptual; Konflik kognitif; Fisika; Pemahaman.

\section{PENDAHULUAN}

Berdasarkan standar kompetensi kurikulum 2013 yang disepakati, pembelajaran harus dilakukan secara tuntas, analisis, dan penerapan konsep. Agar memudahkan peserta didik menerapkan dan menganalisis permasalahan di kehidupan yang tidak lepas dengan konsep fisika. Maka dari itu, standar kompetensi pemahaman konsep fisika sangat dibutuhkan. Pemahaman konsep yang dimiliki siswa adalah penelitian utama dan ekstensif dalam pendidikan fisika. Tujuan pembelajaran fisika disekolah menengah adalah pemahaman konsep dan prinsip yang luas tentang fisika serta memiliki keterampilan dalam mengolah dan mengembangkan ilmu pengetahuan dan tekonologi disertai sikap positif percaya diri sebagai syarat untuk melanjutkan ke pendidikan selanjutnya. Selain itu, fisika menjadi subjek yang penting untuk dipelajari karena membantu peserta didik memiliki kemampuan berpikir dan bertindak secara ilmiah, khususnya untuk mendukung perkembangan zaman dan menanggulangi masalah dalam keseharian (Darmaji, 2019).

Dalam pelajaran fisika pemahaman lebih di utamakan dari pada prestasi belajar. Ketika siswa dapat menghubungkan pengetahuan awal dengan pengetahuan baru, siswa akan menjadi aktif. Akan tetapi menghubungkan kedua pengetahuan tersebut cukup sulit dilakukan oleh siswa. Seringkali ditemukan hambatan dalam mempelajari fisika tidak lain karena anggapan sulit dalam memahami pelajaran fisika, disertai pembelajaran fisika yang kurang menarik (Wulandari dkk, 2018).

Salah satu hambatan dalam pembelajaran fisika adalah kesulitan pemecahan masalah, penyebabnya tidak lain pemahaman yang lemah tentang konsep dan aturan fisika. Dari hasil studi literatur, sebanyak $33 \%$ siswa menganggap pelajaran fisika menantang, sebanyak $55 \%$ menganggap pelajaran fisika sulit dipahami. Sebagian besar mengalami kesulitan dalam pemahaman pelajaran fisika, ketika siswa salah dalam memahami materi, hal ini memicu miskonsepsi. Sehingga banyak dari siswa yang membenci pelajaran fisika (Azizah dkk, 2015).

Miskonsepsi merupakan salah satu permasalahan dalam pembelajaran yang dialami peserta didik maupun guru. Munculnya miskonsepsi dapat karena pengalaman yang dialami peserta didik ketika berinteraksi dengan lingkungannya. Pengalaman yang dimiliki peserta didik tersebut merupakan konsep awal yang di bangun di pikirannya yang belum tentu benar. Jika konsep awal tersebut sudah salah maka sulit untuk memperbaikinya. Untuk mengatasi masalah tersbut harus segera bertindak, agar tidak terjadi kesalahan-kesalahan pada konsep selanjutnya, yang menyebabkan kesulitan untuk memahamai konsep (Andyani dkk, 2013).

Terdapat lima jenis miskonsepsi yaitu, interpretasi konsep awal (preconceved notons), keteguhan tidak rasional (nonscientific beliefs), salah pemahaman konseptual (conceptual misunderstanding), miskonsepsi bahasa (Vernacular misconceptions), realistis miskonsepsi (factual misconceptions). Miskonsepsi akibat faktor siswa sendiri antara lain pengetahuan awal, intusi tidak tepat, tahap perubahan intelektual siswa, kapasitas siswa, afinitas belajar. Faktor miskonsepsi juga berasal dari guru, buku teks dan literatur, metode mengajar. Mengetahui jenis dan faktor miskonsepsi yang terjadi dalam siswa sangat penting untuk menangan permasalahan tersebut (Nurulwati dkk, 2014).

Upaya-upaya yang dilakukan untuk mengurangi miskonsepsi sudah banyak dilakukan, namun hasil upaya tersebut tidak maksimal. Sebelum mengatasi miskonspesi, harus dilakukan terlebih dahulu identifikasi permasalahan dengan membedakan siswa yang miskonsepsi dan tidak tahu konsep. Identifikasi permasalahan yang salah menyebabkan kesalahan dalam mengatasinya. Salah satu upaya untuk mengurangi miskonsepsi adalah menggunakan model pembelajaran perubahan konseptual, dalam model ini peserta didik harus mengubah konsep 
awal mereka melalui penataan kembali atau pemaburan informasi baru ke dalam skema awal. Vosniadou berpendapat bahwa perubahan adalah kombinasi proses kognitif individu dan sosial dan lingkungan yang mereka alami. Prespektif ini menunjukkan bahwa konsepsi akan berubah selama proses perubahan suatu individu dalam menggembangkan konsepsi baru dan mempertahankan konsepsi sebelumnya Potensi secara bersamaan memiliki banyak konsepsi, dapat dijelaskan dengan menggunakan perubahan konseptual (Pebriyanti dkk, 2015).

Perubahan konseptual telah didefinisikan dalam banyak hal. Misalnya dari prespektif Piaget perubahan konspetual melibatkan proses akomodasi, suatu proses dimana skema diubah ketika pelajar mendapatkan informasi baru yang sumbang dengan informasi sebelumnya. Perlu diketahui bahwa dalam akomodasi, skema baru tidak menggantikan skema sebelumnya, skema baru menjadi dominan karena cenderung lebih selaras dengan situasi yang dialami. Dengan demikian, perubahan konseptual didefinisikan dengan menyarankan skema tersbut direstrukturisasi yang mengarah ke perubahan konsepsi sebagai proses pembentukan skema baru. Konsepsi baru yang terbentuk menjadi konsepsi dominan dan yang sebelumnya tidak lagi dianggap, atau bahkan berpotensi hilang. (Mosik \& Maulana, 2010)

Berdasarkan studi literatur upaya mengurangi miskonsepsi banyak dilakukan. Seperti, penerapan model pembelajaran conceptual change dengan melakukan konftontasi terhadap miskonsepsi melalui konflik kognitif (Pebriyanti, Sahidu, \& Sutrio, 2015). Penelitian selanjutnya yang relevan adalah usaha menurunkan miskonsepsi fisika melalui strategi konflik kognitif. (Mosik \& Maulana, 2010).

Teori pemrosesan informasi adalah teori belajar kognitif yang mengungkapkan mengenai pemrosesan, penyimpanan, dan pengambilan keputusan. Teori ini mengungkapkan bagaimana seseorang mengolah informasi dan bisa mengingatnya pada waktu yang panjang. Informasi yang masuk sistem melalui memori sensorik namun dalam jangka waktu yang terbatas. Agar tetap di otak, informasi yang masuk short therm memory akan terhubung dengan long therm memory. Dalam mendapatkan pengetahuan baru harus menyesuikan rangsangan eksternal yang masuk agar sesuai dengan struktur kognitif yang ada. Jika stimulus eksternal informasi baru dalam sistem tidak bermakna maka informasi tidak disimpan sebagai memori. Long therm memory berpotensi kapasitasnya tidak terbatas, sehingga dapat mengakomodasi semua informasi yang sudah dimiliki seseorang. Kelemahan long therm memory adalah sulit untuk mengakses informasi yang sudah tersimpan. Seseorang akan mengalami kesulitan mengakses informasi karena perolehan informasi tidak sempurna. Sehingga banyak yang mengalami kesalahpahaman atau perbedaan konsepsi yang telah disimpan dengan informasi yang baru dimasukkan. (Pratiwi, 2019)

Siswa memiliki sudut pandang mereka sendiri dan konsisten dalam hal penyelesaian masalah tergantung dengan struktur kognitif dan sesuai dengan aturan. Jika terdapat konflik kemungkinan yang pertama adalah siswa dan lingkungannya. Siswa secara sadar atau tidak sadar menangani konflik karena tindakan atau reaksinya tidak sesuai harapan dengan lingkungannya. Bisa jadi karena tidak di benarkan oleh guru, menadapat intruksi yang berbeda, atau tidak bisa menyelesaikan masalah sama sekali. Sehingga konflik kognitif adalah perbedaan konsepsi yang sudah ada dengan informasi baru secara tidak sengaja menimbulkan konflik pada memori seseorang. (Pratiwi, 2019)

Kesalahan peserta didik terkait konsep fisika mengakibatkan tidak tercapainya hasil belajar secara optimal. Dengan pendahuluan yang mendukung diketahui banyak miskonsepsi fisika. Maka dilakukan penelitian pustaka yang bertujuan: (1) mendeskripsikan beban miskonsepsi siswa pada mata pelajaran fisika, (2) mendeskripsikan model pembelajaran conceptual change dapat merubah pemahaman siswa, (3) menganalisis penggunaan pendekatan konflik kognitif untuk menurunkan miskonsepsi siswa pada mata pelajaran fisika.

\section{METODA PENELITIAN}

Penelitian ini menggunakan metoda library research (studi pustaka), mencari sumber literatur yang relevan sesuai topik yang dibahas, dengan tujuan menemukan kajian ilmiah dan teoritis. Mengkaji teori yang sesuai dengan pokok bahasan yaitu tentang peran penggunaan model perubahan konseptual, pendekatan konflik kognitif, serta penurunan miskonsepsi. Penelitian 
ini menggunakan informasi sekunder, informasi yang dikumpulkan berupa hasil penelitian, buku ilmiah, artikel ilmiah, internet dan sebagainya yang sesuai dengan bahasan konflik kognitif. Data yang sudah terkumpul lalu dianalisis.

Model Conceptual Change Dengan Pendekatan Konflik Kognitif Untuk Mengurangi Miskonsepsi Pada Mata Pelajaran Fisika, Teknik analisis data yang digunakan dalam penelitian ini terdiri dari tiga tahapan yaitu organize (mengelompokkan), synthesize (menyatukan), identify (mengidentifikasi), dengan deskripsi sebagai berikut:

1. Organize (Pengorganisasian)

Tahap ini melakukan pengelompokkan literatur - literatur yang dikaji. Literatur harus terlebih dahulu di review sebelum digunakan, agar sesuai dengan pokok bahasan. Selain itu, juga dilakukan perumusan masalah, tujuan, serta pengelompokkan literatur sesuai dengan kategori pokok bahasan.

2. Synthesize (menyatukan)

Pada tahap ini melakukan penyatuan hasil pengelomppokkan literatur secara ringkas dan padu.

Tabel 2. Analisis model perubahan konseptual dengan pendekatan konflik kognitif dalam mengurang miskonsepsi

\begin{tabular}{|c|c|c|c|c|}
\hline No & Nama Artikel & Penulis & Hasil Jurnal & Analisis Telaah \\
\hline 1 & $\begin{array}{l}\text { Cognitve Conflict } \\
\text { Strategy and } \\
\text { Simulation Practicum } \\
\text { to Overcome Student } \\
\text { Misconception on } \\
\text { Light Topics }\end{array}$ & $\begin{array}{l}\text { Warton } \\
\text { o et al. } \\
\text { (2018) }\end{array}$ & $\begin{array}{l}\text { Strategi konflik kognitif yang } \\
\text { dikombinasikan dengan } \\
\text { praktikum simulasi dapat } \\
\text { digunakan untuk mengurangi } \\
\text { kesalahpahaman yang } \\
\text { mengarah pada peningkatan } \\
\text { prestasi belajar siswa. }\end{array}$ & $\begin{array}{l}\text { Strategi konflk kognitif dan } \\
\text { praktkum simulasi } \\
\text { mengurangi kesalahpahaman } \\
\text { dan efektif mengubah } \\
\text { konseptualis siswa ke arah } \\
\text { yang benar. }\end{array}$ \\
\hline 2 & $\begin{array}{l}\text { Conceptual Change } \\
\text { in Science Teaching } \\
\text { and Learning: } \\
\text { Introducing the } \\
\text { Dynamic Model of } \\
\text { Conceptual Change }\end{array}$ & $\begin{array}{l}\text { Louis } \\
\text { S. } \\
\text { Nadels } \\
\text { on. et } \\
\text { al. } \\
(2018)\end{array}$ & $\begin{array}{l}\text { DSCC sebagai media } \\
\text { pembelajaran telah berhasil } \\
\text { mengurangi kesalahpahaman } \\
\text { dalam kategori tinggi, lebih } \\
\text { dari 70\%. }\end{array}$ & $\begin{array}{lr}\text { DSCC dirancang untuk } \\
\text { mematahkan kepercayaan } \\
\text { siswa. Teknik mendongeng } \\
\text { DSCC bisa menjadi media } \\
\text { pembelajaran } & \\
\text { menyelesaikan } & \\
\text { kesalahpahaman. } & \\
\end{array}$ \\
\hline 3 & $\begin{array}{l}\text { Efektifitas } \\
\text { Pembelajaran } \\
\text { Perubahan } \\
\text { Konseptual } \\
\text { Mengatasi } \\
\text { Miskonsepsi } \\
\text { Pada Siswa }\end{array}$ & $\begin{array}{l}\text { Dwi } \\
\text { Pebriya } \\
\text { nti et al. } \\
(2015)\end{array}$ & $\begin{array}{l}\text { Model pembelajaran } \\
\text { conceptual change efektif } \\
\text { dengan kriteria sedang untuk } \\
\text { menangani miskonsepsi fisika } \\
\text { pada materi suhu dan kalor. }\end{array}$ & $\begin{array}{l}\text { Model } \\
\text { pembelajaran conceptual } \\
\text { change untuk menanggulangi } \\
\text { miskonsepsi fisika siswa } \\
\text { adalah model yang mengatasi } \\
\text { miskonsepsi. } \\
\text { siswa dengan melakukan } \\
\text { konfrontasi terhadap }\end{array}$ \\
\hline
\end{tabular}

3. Identify (mengidentifikasi)

Pada tahap ini mengidentifikasi permasalahan yang relevan dan penting untuk ditelaah dan dianalisis, agar menghasilkan paragraf yang ilmiah.

\section{HASIL DAN PEMBAHASAN Organize}

Data yang diperoleh oleh penelti berupa artikel ilmiah yang relevan dengan penelitian adalah sebaigai berkiut:

Tabel 1. Kuantitas pengkategorian jurnal yang teliti

\begin{tabular}{lc}
\multicolumn{1}{c}{ Kategori } & Total \\
\hline Deskripsi Miskonsepsi & 7 \\
\hline $\begin{array}{l}\text { Deskripsi Perubahan } \\
\text { Konseptual }\end{array}$ & 10 \\
\hline Deskripsi Konflik Kognitf & 11 \\
\hline
\end{tabular}

\section{Synthesize}

Hasil telaah beberapa artikel ilmiah dari penelitian yang relevan ditunjukan pada tabel berikut: 


\begin{tabular}{|c|c|c|c|}
\hline & & & $\begin{array}{l}\text { miskonsepsi siswa melalui } \\
\text { konflik kognitif. }\end{array}$ \\
\hline 4 & $\begin{array}{l}\text { Effects of Cognitive } \\
\text { Conflict Instructional } \\
\text { Strategy on Students' } \\
\text { Conceptual Change } \\
\text { in Temperature and } \\
\text { Heat }\end{array}$ & $\begin{array}{ll}\text { B. C. } & \text { Konflik kognitif merupakan } \\
\text { Madu tahap pertama dalam proses } \\
\text { et al. } & \text { conceptual change. CCI } \\
(2015) & \text { berperan besar dalam } \\
& \text { perubahan konseptual siswa. }\end{array}$ & $\begin{array}{l}\text { CCI terdapat tiga langkah } \\
\text { yaitu mengidentifikas kondisi } \\
\text { pengetahuan awal, } \\
\text { menghadapi siswa dengan } \\
\text { informasi yang bertentangan, } \\
\text { mengevaluasi ringkat } \\
\text { perubahan sebelum dan } \\
\text { sesudah test. }\end{array}$ \\
\hline 5 & $\begin{array}{l}\text { Fotonovela with } \\
\text { Cognitive } \\
\text { Conflict } \\
\text { Approach as } \\
\text { Media to } \\
\text { Discloses The } \\
\text { Easy and } \\
\text { Difficult } \\
\text { Remedied } \\
\text { Misconception }\end{array}$ & $\begin{array}{ll}\text { Arista Penurunan kesalahpahaman } \\
\text { Rahayu et sebesar } 14,81 \% \text { menunjukkan } \\
\text { al. (2018) bahwa media fotonovela } \\
\text { dengan pendekatan konflik } \\
\text { kognitif dapat digunakan untuk } \\
\text { memecahkan masalah dan } \\
\text { dapat memulihkan } \\
\text { kesalahpahaman. }\end{array}$ & $\begin{array}{l}\text { Implementasi media } \\
\text { fotonovela menggunakan } \\
\text { strategi konflik kognitif dapat } \\
\text { menurunkan proporsi siswa } \\
\text { yang mengalami } \\
\text { kesalahpahaman pada konsep } \\
\text { kinomatik gerak lurus. }\end{array}$ \\
\hline 6 & $\begin{array}{l}\text { Identifikasi } \\
\text { Miskonsepsi Dan } \\
\text { Konflik Kognitif } \\
\text { Fisika: Kasus Terkait } \\
\text { Perubahan } \\
\text { Konseptual }\end{array}$ & $\begin{array}{ll}\text { Zul } & \text { Miskonsepsi masih terjadi, } \\
\text { Hidaya } & \text { siswa belum mampu melalui } 4 \\
\text { tullah } & \text { proses berpkir yakni tahapan } \\
\text { et al. perubahan konsep. } \\
(2020)\end{array}$ & $\begin{array}{l}\text { Konflik kognitif berbanding } \\
\text { lurus dengan perubahan } \\
\text { konseptual, } r \text { dengan } \\
\text { berbantuan media membantu } \\
\text { proses perubahan konseptual. }\end{array}$ \\
\hline 7 & $\begin{array}{l}\text { On the Cognitive } \\
\text { Conflict as an } \\
\text { Instructional } \\
\text { Strategy for } \\
\text { Conceptual Change: } \\
\text { a Critical Apprasial }\end{array}$ & $\begin{array}{lll}\text { Limon } & \text { Konflik kognitif berhasil } \\
\text { Margar } & \text { terjadi pada siswa dan } \\
\text { ita } & \text { menjadikan informasi yang } \\
(2001) & \text { bermakna, maka dengan } \\
& \text { mudah terjadi perubahan } \\
& \text { konseptual. }\end{array}$ & $\begin{array}{l}\text { Strategi instruksional } \\
\text { perubahan konseptual yang } \\
\text { paling umum diterapkan di } \\
\text { kelas adalah untuk } \\
\text { menginduksi konflik kognitif } \\
\text { melalui penyajian data yang } \\
\text { anomali atau informasi yang } \\
\text { kontradiktif. }\end{array}$ \\
\hline 8 & $\begin{array}{l}\text { Utilization of } \\
\text { Cognitive Conflict } \\
\text { Instructional } \\
\text { Strategy and } \\
\text { Conceptual Change } \\
\text { Pedagogy for } \\
\text { Enhancement of } \\
\text { Students' Attention } \\
\text { in Physics }\end{array}$ & $\begin{array}{l}\text { Konflik kognitif dan pedagogi } \\
\text { perubahan konseptual } \\
\text { memupuk perhatian siswa dan } \\
\text { fokalisasi pemahaman fisika } \\
\text { termal lebih dari strategi } \\
\text { pembelajaran tradisional. }\end{array}$ & $\begin{array}{lr}\text { Strategi } & \text { pembelajaran } \\
\text { konseptual } & \text { mengubah } \\
\text { pedagogi } & \text { siswa, dapat } \\
\text { mengambil } & \text { alih } \\
\text { kesalahpahaman } & \text { siswa tetang } \\
\text { fisika termal. } & \end{array}$ \\
\hline 9 & $\begin{array}{l}\text { Penerapan } \\
\text { Conceptual Change } \\
\text { Model Untuk } \\
\text { Mereduksi } \\
\text { Miskonsepsi Siswa } \\
\text { Pada }\end{array}$ & $\begin{array}{l}\text { Model Perubahan konseptual } \\
\text { memliki efektivitas yang tinggi } \\
\text { dalam mereduksi miskonsepsi. }\end{array}$ & $\begin{array}{l}\text { Terjadinya perubahan } \\
\text { konseptual mengindikasikan } \\
\text { bahwa siswa mampu } \\
\text { mengubah miskonsepsinya ke } \\
\text { konsep yang benar secara } \\
\text { ilmiah. }\end{array}$ \\
\hline
\end{tabular}




\begin{tabular}{|c|c|c|c|c|}
\hline & $\begin{array}{l}\text { Materi Suhu Dan } \\
\text { Kalor }\end{array}$ & & & \\
\hline 10 & $\begin{array}{l}\text { Pengaruh Strategi } \\
\text { Konflik Kognitif } \\
\text { Ditinjau dari } \\
\text { Kemampuan Awal } \\
\text { Siswa untuk } \\
\text { Mengurangi } \\
\text { Miskonsepsi pada } \\
\text { Materi Gelombang } \\
\text { Mekanik }\end{array}$ & $\begin{array}{l}\text { Nurwid } \\
\text { ya } \\
\text { Hasana } \\
\text { h et al. } \\
(2020)\end{array}$ & $\begin{array}{l}\text { Strategi konflik kognitif } \\
\text { mengakibatkan penurunan } \\
\text { drastis terhadap miskonsepsi, } \\
\text { kemampuan awal } \\
\text { mempengaruh penurunan } \\
\text { miskonsepsi. }\end{array}$ & $\begin{array}{l}\text { Pembelajaran dengan } \\
\text { memunculkan permasalahan } \\
\text { pada struktur kognitif efektif } \\
\text { mampu menyelesaikan } \\
\text { masalah secara mandiri. }\end{array}$ \\
\hline 11 & $\begin{array}{l}\text { Penggunaan } \\
\text { Pendekatan Konflik } \\
\text { Kognitif Untuk } \\
\text { Remediasi } \\
\text { Miskonsepsi } \\
\text { Pembelajaran Suhu } \\
\text { Dan Kalor }\end{array}$ & $\begin{array}{l}\text { Nana } \\
(2018)\end{array}$ & $\begin{array}{l}\text { Remidiasi dengan pendekatan } \\
\text { konflik kogntif mampu } \\
\text { mengurangi ketdaktepatan } \\
\text { konsepsi mengenai suhu dan } \\
\text { kalor. }\end{array}$ & $\begin{array}{l}\text { Pendekatan konflik kogntif } \\
\text { membutuhkan peran guru agar } \\
\text { dapat mengubah struktur } \\
\text { kognitif yang salah menjadi } \\
\text { benar, menjadikan siswa } \\
\text { mampu mengevaluasi mandiri } \\
\text { yang perlu di perbarui. }\end{array}$ \\
\hline 12 & $\begin{array}{l}\text { Peningkatan } \\
\text { Penguasaan Konsep } \\
\text { Fisika Dasar Materi } \\
\text { Suhu dan Kalor } \\
\text { Melalui Pendekatan } \\
\text { Konflik Kognitif }\end{array}$ & $\begin{array}{l}\text { Muham } \\
\text { mad } \\
\text { Zuhdi } \\
\text { et al. } \\
(2020)\end{array}$ & $\begin{array}{l}\text { Pendekatan konflik kognitif } \\
\text { efektif menambah kapabilitas } \\
\text { konsep suhu dan kalor dengan } \\
\text { kategori tinggi dan sedang. }\end{array}$ & $\begin{array}{l}\text { Strategi konflik kognitif } \\
\text { mampu menambah kapabilitas } \\
\text { konsep dengan baik, dan } \\
\text { mudah menerima konsep yang } \\
\text { diajarkan. }\end{array}$ \\
\hline 13 & $\begin{array}{l}\text { Peranan Konflik } \\
\text { Kognitif Terhadap } \\
\text { Perubahan } \\
\text { Konseptual Pada } \\
\text { Mahasiswa Tentang } \\
\text { Konsep Gaya }\end{array}$ & $\begin{array}{l}\text { Muh. } \\
\text { Makhr } \\
\text { us. } \\
(2018)\end{array}$ & $\begin{array}{l}\text { Model pembelajaran CCM } \\
\text { CCA mampu memperbesar } \\
\text { konflik kognitif dan } \\
\text { modifikasi argumen terhadap } \\
\text { pemikiran yang salah dan } \\
\text { meyakini kebenaran dari } \\
\text { konsepsi ilmiah. }\end{array}$ & $\begin{array}{l}\text { Tinggnya kepercayaan } \\
\text { terhadap kebenaran konsep } \\
\text { menjadikan tingkat konflik } \\
\text { kognitif yang terjadi tinggi. } \\
\text { Perubahan konseptual } \\
\text { prosesnya lambat dan } \\
\text { bertahap sampai keyakinan } \\
\text { tentang konsep ilmiah tinggi. }\end{array}$ \\
\hline 14 & $\begin{array}{l}\text { Cognitive Conflict } \\
\text { and Situational } \\
\text { Interest as Factors } \\
\text { Influencing } \\
\text { Conceptual Change }\end{array}$ & $\begin{array}{l}\text { Hunsik } \\
\text { Kang } \\
\text { et all. } \\
(2010)\end{array}$ & $\begin{array}{l}\text { Konflik kognitif tidak langung } \\
\text { berdampak terhadap } \\
\text { konseptual siswa, } \\
\text { membutuhkan media yang } \\
\text { menarik perhatian agar dapat } \\
\text { mempengaruhi konseptual } \\
\text { siswa. }\end{array}$ & $\begin{array}{l}\text { Sistuasi lingkungan } \\
\text { berpengaruh kuat pada } \\
\text { perubahan konseptual siswa } \\
\text { dari pada konflik kognitif, } \\
\text { baik secara langsung maupun } \\
\text { tidak langsung dapat } \\
\text { mempengaruhi pemahaman } \\
\text { konseptual. }\end{array}$ \\
\hline 15 & $\begin{array}{l}\text { Conceptual Change } \\
\text { in Science: A Process } \\
\text { of Argumentation }\end{array}$ & $\begin{array}{l}\text { George } \\
\text { Zhou. } \\
\text { (2010) }\end{array}$ & $\begin{array}{l}\text { Model } \\
\text { menggabungkan kontribusi } \\
\text { pendidik sains dan psikolog } \\
\text { pendidikan untuk perubahan } \\
\text { konseptual pedagogi dan } \\
\text { memiliki potensi untuk } \\
\text { memajukan pemahaman } \\
\text { tentang topik tertentu. }\end{array}$ & $\begin{array}{lr}\text { Secara } & \text { epistemologis, } \\
\text { penggunaan } & \text { argumen } \\
\text { membantu siswa untuk } \\
\text { merasa tidak puas dengan } \\
\text { prakonsepsi. } \\
\text { pedagogis, Secara } \\
\text { argumen akan memotivasi } \\
\text { siswa untuk lebih terlibat } \\
\text { dalam proses pembelajaran. }\end{array}$ \\
\hline
\end{tabular}




\section{Identify}

Sebanyak $51 \%$ siswa di 3 sekolah yaitu, SMA Negeri 1 Bangil, SMA YADIKA Bangil, dan SMA Negeri 8 Malang menganggap fisika tidak mudah dipahami. Sebagian besar mengatakan bahwa fisika terlalu banyak rumus dan banyak konsep. Pengajaran yang kurang maksimal seperti metode pembelajaran yang kurang tepat, guru yang terlalu cepat dalam menerangkan, atau kurangnya stimulus dalam mengajar menjadikan pembelaran fisika dalam kelas membosankan. Situasi dalam pembelajaran yang kurang mendukung menyebabkan siswa merasakan kesulitan bahkan membenci pelajaran fisika. Dari beberapa materi, kebanyakan siswa menganggap sulit di materi suhu dan kalor dengan presentase $26 \%$, materi optik $25 \%$, Fluda statis $21 \%$, Elastisitas dan Hukum Hooke $17 \%$, dan Kinematika $11 \%$. Materi suhu dan kalor memiliki konsep yang sangat abstrak sehingga dapat memunculkan berbagai pemikiran yang berbeda ketika siswa mempelajarinya. Sehingga siswa rawan mengalami miskonsepsi atau pemahaman yang tidak sesuai dengan yang sebenarnya. Sebanyak $32 \%$ siswa mengalami kesulitan menyelesaikan permasalahan soal, dan $26 \%$ kesulitan memahami konsep dan rumus. Kesulitan pemecahan perkara ditimbulkan lemahnya pemahaman fondasi dan kaidah fisika, kurangnya menafsirkan soal, dan sedikit ambisi siswa (Azizah dkk, 2015).

Tanpa disadari pada proses pembelajaran siswa mengalami proses asimilasi dan akomodasi. Kedua proses tersebut berperan mampu merubah konseptual siswa jika adanya rangasangan konflik kognitif. Agar siswa mengalami perubahan konseptual maka ada 4 kondisi yang perlu dilalui yaitu: ketidakpuasan dengan konsep yang ada, kejelasan konsep baru, logika konsep baru, keberhasilan menghargai konsep baru (Nadelson et al. 2018). Guru yang berhasil meyakinkan prakonsepsinya bertentangan dengan konsep ilmiah maka akan dapat mengarahkan siswa ke perubahan konseptual. Menyadari keadaan yang salah dan kemauan untuk merubah konsepsi merupakan hal yang utama dalam perubahan konseptual (Hidayatullah \& Junadi, 2020).

Ada banyak cara untuk mengidentifkasi adanya perubahan konseptual, salah satunya dengan wawancara terstruktur. Wawancara bertujuan mengetahui proses berpikir siswa serta mengamati kesalahpahaman siswa (Hidayatullah
\& Junadi, 2020). Dapat dilakukakan dengan pendekatan konflik kognitif. Hasil analisis FGD menghasilkan model pembelajaran perubahan konseptual dengan pendekatan konflik kognitif (MPK - PKK), dalam model ini di rancang menjadi 8 fase/sintaks. Menggunakan model ini memicu siswa aktif dalam kelas (Makhrus dkk, 2014). Penelitian menggunakan model pembelajaran perubahan konseptual untuk mereduksi miskonsepsi dengan konfontrasi terhadap miskonsepsi dengan pendekatan konflik kognitf. Keberhasilan menurunkan miskonsepsi sebesar $17.5 \%$ dan $\mathrm{N}$-gain sebesar 0.65 masuk dalam kriteria sedang, mengindikasikan bahwa model pembelajaran conceptual change efektif dengan kriteria sedang untuk menangani miskonsepsi fisika pada materi suhu dan kalor.

Model pembelajaran conceptual change (CCM-CCA) meningkatkan proses konflik kognitif pada saat pembelajaran sehingga siswa aktif terlibat membangun konsepsinya sendiri (Muh, 2018). Hasil penelitian menunjukkan model perubahan konseptual memiliki efisiensi yang tinggi dalam mereduksi miskonspesi siswa XI IPA SMAN 2 Teluk Keramat dengan perhitungan DQM sebesar $71.57 \%$ (Dedi dkk, 2019).

Strategi konflik kognitif dapat mengurangi kesalahpahaman siswa karena strategi ini adalah strategi perubahan konseptual yang memungkinkannya untuk mengacaukan kesalahpahaman siswa terhadap konsep ilmiah dan konsepsi ilmiah yang telah siswa jalankan untuk belajar prestasi melalui penyediaan contoh kontra, analogi, demonstrasi dan eksperimen. Hal ini juga didukung melalui beberapa keunggulan yang dimiliki oleh strategi ini, antara lain memperhatikan konsepsi siswa yang salah, memperhatikan interaksi antar konsep, mengikutsertakan siswa secara aktif, membantu siswa dalam menafsirkan sebuah konsep dan menyematkan konsep aktual dengan benar dan jangka panjang (Warono dkk, 2018).

Konflik kognitif merupakan kondisi rekognisi suatu informasi terdapat perbedaan antara struktur kognitif seorang dan lingkungan (informasi eksternal), atau konsepsi, keteguhan, substruktur, dll. struktur kognitif seseorang. Konflik kognitif dalam teori klasik adalah "revolusioner" proses yang diyakini membuat peserta didik menerima konsepsi dengan tidak 
puas dengan konsepsi mereka saat tidak dapat memenuhi ketentuan untuk konsepsi ilmiah. Konflik kognitif terbentuk saat ekuilibrium mental terusik oleh pengalaman atau menjadi data anomali yang tidak sinkrom dengan interpretasi yang ada (Madu \& Orji, 2015).

Strategi konflik kognitif menyertakan (a) menandai status wawasan siswa terkini; (b) menghadapi informasi kontradiktif siswa yang dipaparkan melalui interview dan teks, sehingga mejadikan eksplisit konflik, atau memandu diskusi antar siswa, dan (c) menguji derajat perubahan konseptual antara pendapat sebelumnya dan skala posttest sesudah instruksional intrusi. Untuk memahami konflik kognitif, pengetahuan tentangmodel proses konflik sangat penting. Alasannya adalah karena menjelaskan tahapan di mana konflik kognitif terjadi dan cara mengatasi konflik yang dihasilkan (Madu \& Orji, 2015).

\section{KESIMPULAN}

Permasalahan yang umum dihadapi siswa adalah miskonsepsi. Miskonsepsi dapat berasal dari siswa, guru, buku, dan lain - lain. Beban Miskonsepsi yang dimiliki siswa rata rata tinggi dalam pelajaran fisika terutama dalam materi suhu dan kalor. Upaya menurunkan tingkat miskonsepsi salah satunya adalah dengan mengubah konsepsi siswa menggunakan strategi konflik kognitif.

Penggunaan model pembelajaran perubahan konseptual dengan strategi konflik kognitif berdampak positif dalam pembelajaran diantaranya, menjadikan siswa aktif dalam menyelesaikan permasalahan secara mandiri, dapat mengubah pemahaman yang perlu di perbaru, membuat pelajaran menjadi bermakna, signifikan terhadap penurunan miskonsepsi, dapat memperbarui konsep, serta meningkatkan pemahaman dan hasil belajar.

penurunan miskonsepsi, memperbarui konsep, serta meningkatkan pemahaman dan hasil belajar.

\section{UCAPAN TERIMA KASIH}

Terima kasih penulis ucapkan atas pihak yang telah mendukung, memotivasi, memberi saran, kritik, dalam penyusunan artikel ilmiah ini, diantaranya:
1) Dr. Munasir, S. Si., M.Si. selaku Ketua Jurusan Fisika

2) Nadi Suprapto, Ph. D. selaku Ketua Prodi Pendidikan Fisika

3) Ayah, ibu, dan saudara atas doa dan dukungan

4) Teman - teman Fisika dan Organisasi PKPT yang menginspirasi.

\section{DAFTAR PUSTAKA}

Achor, Emmanuel E., \& Peter A, Yakubu. (2020). Utilization of Cognitive Conflict Instructional Strategy and Conceptual Change Pedagogy for Enhancement of Students' Attention in Physics. ICSHER JOURNAL, 4(3), 1-22.

Adnyani, Ni Wayan., Sadia, I wayan., Natajaya, I Nyoman. (2013). Pengaruh Strategi Pembelajaran Konflik Kognitif Terhadap Penurunan Miskonsepsi Fisika Ditinjau Dari Gaya Kognitif Siswa Kelas X Di SMAN 1 Bebandem. e-Journal Program Pascasarjana Universitas Pendidikan Ganesha, 4(1), 1-11.

Alfiani. (2015). Analisis Profil Miskonsepsi dan Konsistensi Konsepsi Siswa SMA pada Topik Suhu dan Kalor. Prosiding Seminar Nasional Fisika (E-Journal) SNF2015, IV, 29-32.

Azizah, R.., Yuliati, L., \& Latifah, E. (2015). Kesulitan Pemecahan Masalah Fisika Pada Siswa SMA. Jurnal Penelitian Fisika dan Aplikasinya, 5(2), 44-50.

Darmaji, D., Astalini, A., Kurniawan, D.A., \& Perdana, R., \& Putra, D.S. (2019). A study relationship attitude toward physics, motivation, and character discipline students senior high school, in Indonesia. International Journal of Learning and Teaching, 11(3), 99-109.

Dedi, Sahala S S., \& Hamdani. (2019). Penerapan Conceptual Change Model Untuk Mereduksi Miskonsepsi Siswa Pada Materi Suhu dan Kalor. Jurnal Untan, 7(11), 1-10.

Hasanah, N., Hidayat, A., \& Koeshandayanto, S. (2020). Pengaruh Strategi Konflik 
Kognitif Ditinjau dari Kemampuan Awal Siswa untuk Mengurangi Miskonsepsi pada Materi Gelombang Mekanik. Jurnal Universitas Negeri Malang, 5(5), 624629.

Hidayatullah, Z., Junadi., Nadhiroh, Nuraini., Kartika, Endah., Ainun N, Azizah., \& Yunior E, Sony. (2020). Identifikasi Miskonsepsi dan Konflik Kognitif Fisika: Kasus Terkait Perubahan Konseptual. EDUSAINS, 12(1), 64-71.

Kang, Hunsik., Scharmann, Lawrence C., Kang, Sukjin., \& Noh, Taehee. (2010). Cognitive Conflict and Situational Interest as Factors Influencing Conceptual Change. International Journal of Environtmental \& Science Education, 5(4), 383-405.

Kuezmann, I. (2017). The Structure of Knowledge and Students' Misconceptions in Physics. AIP Conference Proceedings. New York: AIP.

Limon, Margarita. (2001). On the Cognitive Conflict as an Instructional Strategy for Conceptual Charge: a Critical Apprasial. Elsevier, 11(4-5), 357-380.

Madu, B. C., \& Orji, E. (2015). Effects of Cognitive Conflict Instructional Strategy on Students' Conceptual Change in Temperature and Heat. CA: SAGE.

Makhrus, M., Nur, M., \& Widodo, W. (2014). Model Perubahan Konseptual Dengan Pendekatan KonfliK Kognitif. Jurnal Pijar Mipa, IX(1), 20-25.

Mosik, P., \& Maulana. (2010). Usaha Mengurangi Terjadinya Miskonsepsi Fisika Melalui Pembelajaran Dengan Pendekatan Konflik Kognitif. Jurnal Pendidikan Fisika Indonesia , Vol 6 ,98-103.

Muh, M. (2018). Peranan Konflik Kognitif Terhadap Perubahan Konseptual Pada Mahasiswa Tentang Konsep Gaya. Konstan Jurnal Fisika Dan Pendidikan Fisika. 3(1), 1-8.
Nana. (2018). Penggunaan Pendekatan Konflik Kognitif Untuk Remediasi Miskonsepsi Pembelajaran Suhu Dan Kalor. Surakarta: SNPS.

Nurulwati, Veloo, A., \& Mat A, R. (2014). Suatu Tinjauan Tentang Jenis - Jenis dan Penyebab Miskonsepsi Fisika. Jurnal Pendidikan Sains Indonesia, 2(1), 87-95.

Pebriyanti, D., Sahidu, H., \& Sutrio. (2015). Efektifitas Model Pembelajaran Perubahan Konseptual Untuk Mengatasi Miskonsepsi Fisika Pada Siswa Kelas X SMAN 1 Praya Barat Tahun Pelajaran 2012/2013. Jurnal Pendidikan Fisika dan Teknologi, 1(1), 92-96.

Pratiwi, E. (2019). Characteristics of Students' Cognitive Conflict in Solving a Problem Based on Information Processing Theory. International Journal of Learning, Teaching and Educational Research, 18 (2), 76-88.

Rahayu, A., Hartono, \& Sutikno. (2018). Fotonovela with Cognitive Conflict Approach as Media to Discloses The Easy and Difficult Remedied Misconception. Jurnal UNNES, 2(1), 36-45.

Nadelson, Louis S., C Heddy, Benjamin., Jones, Suzanne., Taasoobshirazi, Gita., \& Jhonso, Marcus. (2018). Conceptual Change in Science Teaching and Learning: Introducing the Dynamic Model of Conceptual Change. IJEPInternational Journal of Educational Psycoloogy, 7(2), 151-195.

Wartono., Batlolona, John Rafafay., \& Putirulan, Apilya. (2018). Cognitive Conflict Strategy and Simulation Practicum to Overcome Student Misconception on Light Topics. Journal of Education and Learning (EduLearn), 12(4), 747-756.

Wulandari, T. A., Prihandono, T., \& Maryani. (2018). Analisis Miskonsepsi Siswa Pada Materi Suhu dan Kalor Di Kelas XI SMA Jember. Seminar Nasional Pendidikan Fisika, 3(1), 135-139. 
Zuhdi, M., \& Makhrus, M. (2020). Peningkatan Penguasaan Konsep Fisika Dasar Materi Suhu dan Kalor Melalui Pendekatan Konflik Kognitif. Kappa Journal, 4(1), 37-41.

Zhou, George., (2010). Conceptual Change in Science: A Process of Argumentation. Eurasia Journal of Mathematic, Science \& Technology Education, 6(2), 101-110. 